\title{
A experiência de integração ensino-serviço no trabalho em saúde materno e infantil da regional Centro Sul: Pet GraduaSUS do curso de Gestão de Serviços de Saúde/UFMG
}

Thais Cadar, Maria Silvia Ribeiro, Simone Couto, Kátia Ferreira Costa Campos, Keli Bahia Felicíssimo Zocratto

\section{Resumo}

Introdução: A educação permanente (EP) envolve a promoção do pensamento crítico e produtivo dos trabalhadores e gestores visando potencializar a resolutividade das ações. Uma de suas estratégias é a aprendizagem a partir das práticas e da construção de novos significados para os processos de trabalho, fundamentadas na andragogia, no respeito às particularidades loco-regionais, na lógica de construção das necessidades de forma ascendente e coletiva de maneira a contemplar as prioridades definidas pela gestão e no monitoramento dos processos de aprimoramento e formação profissional. No contexto da educação permanente e sua interface na relação ensinoserviço, o Programa de Educação pelo Trabalho em Saúde (PET Saúde) tem proporcionado aprendizado aos profissionais de saúde e acadêmicos, na forma de vivências e estágios, que contemplam as necessidades do SUS de educação pelo trabalho. As atividades de aprendizagem são coordenadas por tutores (professores universitários) que, em articulação com os preceptores (profissionais de áreas da rede municipal de saúde) e alunos de graduação, constituem a equipe de atuação no PET Saúde. As ações desenvolvidas apresentam foco na interdisciplinaridade e interprofissionalidade, na integração ensino/serviço/comunidade, na humanização do cuidado, na integralidade da assistência, no desenvolvimento das atividades que considerem a diversificação de cenários de práticas e redes colaborativas na formação para o SUS. O Pet Gradua SUS do Curso de Gestão de Serviços de Saúde (CGSS) se desenvolve em parceria da Secretaria Municipal de Saúde (SMSA) de Belo Horizonte com a Universidade Federal de Minas Gerais (UFMG) e buscou delinear uma formação diferenciada para o trabalho no SUS, fortalecido pela prática e EPS. Objetivo: Relatar a vivência do PET Gradua SUS nos processos de integração ensino/serviço/comunidade. Métodos: Trata-se de um relato de experiência da proposta desenvolvida pelo PET GraduaSUS do Curso de Gestão de Serviços de Saúde/UFMG (início: maio/2016 e término: fevereiro/2018). Utilizou-se a metodologia participativa com a coparticipação dos diferentes atores sociais envolvidos no processo, e valorização do saber local interagindo com o saber científico. As ações estabelecidas estiveram vinculadas ao ciclo de vida Materno-Infantil do município de Belo Horizonte, e foram delineadas a partir de diagnósticos situacionais realizados no distrito Centro Sul, com posterior desenvolvimento de projetos de intervenção. Optou-se pelo Planejamento Estratégico Situacional tendo como campos de atuação os Centros de Saúde Nossa Senhora Aparecida, Nossa Senhora de Fátima e a Gerência Regional de Atenção à Saúde Centro Sul (GERASA CS). Este método valoriza o cotidiano do serviço assim como a interpretação de cada indivíduo/ator da situação problema, mediante suas crenças, experiências e posição no jogo social. Resultados: O bloco relativo à Saúde Materna e Infantil é composto por 7 indicadores: Número de mortes maternas; Número de óbitos potencialmente evitáveis; Proporção de gestantes captadas até o final do $1^{\circ}$ trimestre; Proporção de gestantes acompanhadas no pré-natal; Média de atendimento de puericultura em menores de 2 anos; Percentual de crianças atendidas aleitamento materno exclusivo; Percentual de recém-nascidos atendidos na primeira semana de vida (PMAQ). O projeto desenvolveu-se por fases. A primeira fase envolveu a composição do grupo pelos alunos bolsistas 
ISSN 2179-6750

do PET e preceptores dos Centros de Saúde e da GERASA CS. Consistiu na preparação do grupo de alunos familiarizando-os acerca dos indicadores escolhidos e protocolos assistenciais relacionados. O grupo teve o apoio das tutoras e supervisoras realizando um levantamento documental, relativo aos indicadores selecionados e seus respectivos protocolos assistenciais; e elaboração de checklist para observação do processo de trabalho. Na segunda etapa foi proposto um levantamento de dados e organização dos resultados dos indicadores para análise, composta pela elaboração do diagnóstico relacionado à assistência da criança até 02 anos de idade e à gestante. Foram escolhidos 06 indicadores, quais sejam: razão de mortalidade materna, taxa de mortalidade infantil, proporção de gestantes captadas até o final do primeiro quadrimestre, proporção de gestantes acompanhadas no pré-natal. Posteriormente foi realizado a busca dos dados no Sistema de Informações em Saúde (SIS Rede - SMS-BH) para elaboração de gráficos e tabelas, além da análise descritiva. A terceira fase contou com discussões envolvendo as Equipes de Saúde da Família dos Centros de Saúde participantes para o compartilhando dos resultados e delineamento de possíveis propostas de intervenção. A articulação ensino- serviço foi essencial para a elaboração, levantamento e desenvolvimento de projetos de melhoria. Estes projetos foram definidos juntamente com as equipes e gerência da unidade, tendo a participação ativa dos alunos nessa interlocução, como protagonistas das ações, proporcionando interesse e engajamento nos projetos. Ao proporcionar a vivência ativa do aluno no processo formativo, a experiência relatada garante o nexo com a realidade, a partir da compreensão e ação crítica, sendo o tutor e o supervisor no PET Gradua-SUS, facilitadores do processo de aprendizado. Neste contexto, o cenário estabelecido favorece a troca de conhecimentos e experiências entre os atores envolvidos que, mediatizados pela realidade do serviço, como diz Paulo Freire, se educam. "Já agora ninguém educa ninguém, como tampouco ninguém se educa a si mesmo: os homens se educam em comunhão mediatizados pelo mundo". Nesta fase, questões administrativas que envolveram troca de gerência no Centro de Saúde Nossa Senhora Aparecida, interferiram no seguimento do projeto nesta unidade. No entanto, o PET deu continuidade às ações propostas no Centro de Saúde Nossa Senhora de Fátima que, na primeira fase, contou com a participação dos bolsistas na oficina realizada pela Estratégia Amamenta e Alimenta Brasil (EAAB). Em seguida, levantaram-se os dados para cálculo dos indicadores materno-infantis por equipes com elaboração de gráficos. A partir da análise dos dados em conjunto com as equipes houve a seleção dos problemas prioritários, a saber: "Perda de oportunidade para Ações do Quinto dia" e "Baixos índices de aleitamento materno". Seguiu-se com a elaboração do plano de ação utilizando-se a estratégia 5W2H.Todo o processo foi integrado entre Distrito Sanitário e Unidade Básica de Saúde. A quarta fase foi norteada pela implementação dos projetos de intervenção - apoio às equipes- fase atual do projeto que já conta com um grupo mensal de gestantes, com rodas de conversas envolvendo o aleitamento materno como tema transversal abrangendo o autocuidado e direitos das gestantes. As decisões no coletivo das equipes proporcionou o envolvimento das Equipes de Saúde da Família e NASF. A preparação dos ACSs está em fase de planejamento visando as visitas de captação do recém- nascido para as ações do quinto dia. Por fim, a quinta fase: acompanhamento e avaliação - observação com utilização do roteiro construído na primeira fase, levantamento de dados e cálculo de indicadores do período de execução do projeto Pet-Gradua-SUS, com avaliação conjunta com as ESFs. Conclusões: A experiência proporcionada ao aluno uma vivência articulada das ações desenvolvidas pelos níveis de gestão local e regional (Centros de Saúde e Gerência Regional) contribui para sua formação profissional, uma vez que apresenta uma visão ampliada do cenário em saúde. Visando a continuidade das ações após o término do projeto PET-GraduaSUS-Gestão foi realizada uma parceria envolvendo a disciplina de estágio curricular entre os Curso de Gestão de Serviços de Saúde e Curso de Enfermagem da UFMG. Outra experiência proporcionada pelo PET que deve ser incorporada às práticas acadêmicas diz respeito ao processo de avaliação do aluno, que se deu de modo formativo, visando o desenvolvimento do mesmo no decorrer do projeto, por meio de 
ISSN 2179-6750

reuniões periódicas.

Descritores: Educação, Educação Permanente, Políticas Públicas, Gestão em Serviços, indicadores básicos de saúde 